\title{
Generalised scepticism: How people navigate news on social media
}

\author{
Richard Fletcher $^{\mathrm{a} *}$ and Rasmus Kleis Nielsen ${ }^{\mathrm{b}}$
}

${ }^{a}$ Reuters Institute for the Study of Journalism, Department of Politics and International Relations, University of Oxford, 13 Norham Gardens, Oxford, OX2 6PS.

richard.fletcher@politics.ox.ac.uk+44(0)1865 611075

${ }^{b}$ Reuters Institute for the Study of Journalism, Department of Politics and International Relations, University of Oxford, 13 Norham Gardens, Oxford, OX2 6PS.

rasmus.nielsen@politics.ox.ac.uk +44 (0)1865 611074

*Corresponding author

Richard Fletcher (PhD) is a Research Fellow at the Reuters Institute for the Study of Journalism, University of Oxford. He is lead researcher and co-author of the Reuters Institute Digital News Report.

Rasmus Kleis Nielsen $(\mathrm{PhD})$ is Professor of Political Communication and Director of Research at the Reuters Institute for the Study of Journalism, University of Oxford. He is Editor in Chief of the International Journal of Press/Politics and co-author of the Reuters Institute Digital News Report.

\section{Generalised scepticism: How people navigate news on social media}

Social media is an increasingly widely-used and important source of news. News on social media is 'selected' by a variety of actors, including the editors and journalists 
that produce the content, and the algorithms developed by technology companies to make automatic display decisions based on users' past behaviour and the actions of their friends. We analyse how people navigate news on social media, and focus on their perception of the different kinds of news selection involved. The analysis uses a mixedmethods design based on focus group material and survey data from Germany, Spain, the United Kingdom, and the United States. Across all four countries, with their different political and media systems, we find (i) that the majority do not understand exactly how the information they receive is filtered by algorithms, but they do not uncritically accept it either, because they are sceptical of all forms of selectionincluding that performed by editors and journalists, (ii) that approval for algorithmic selection is stronger amongst younger people, and (iii) that those with a high level of interest in 'soft' news topics (and a low interest in 'hard' news topics) are more likely to approve of news algorithmically selected on the basis of what their friends have consumed. We argue that the way in which most people navigate news on social media is thus based on a 'generalised scepticism' where people questions all kinds of selection.

Keywords: news; social media; news selection; algorithms; journalism; generalised scepticism

Historically, what people commonly understand as 'the news' was selected by editors and journalists. Some hypothesised that the development of digital media would collapse this role, because journalists would have less and less control over the flow of information, and new technologies would enable people to share things without relying on mass media (Williams \& Delli Carpini, 2011). This does not seem to have happened, as established news media are still the most important and widely used producers of news (Newman, Fletcher, Kalogeropoulos, Levy, \& Nielsen, 2017). Instead, we appear to be moving to an environment in which editorial selection is increasingly itself subjected to a further selection by algorithms used by the search engines, messaging apps, aggregators, and social media.

Social media in particular is becoming increasingly important. One 2016 survey found that over half (51\%) of online news consumers across 26 countries use social media platforms, such as Facebook, Twitter and LinkedIn, to access news (Newman, Fletcher, 
Levy, \& Nielsen, 2016). Similarly, a report from the Pew Research Centre (2016) stated that $44 \%$ of people in the United States 'sometimes' or 'often' use social media to get news. For the most part, social media companies do not produce their own news content, but instead act as platforms that connect their users with news publishers (and many other third parties). In some countries, accessing and finding news via social media is now more widespread than going direct to the websites and apps of news organizations themselves (Newman et al., 2017) and publishers are increasingly reliant on referrals from social media companies (Nielsen \& Ganter, 2018).

This means that a new set of actors — which some might think of as secondary 'gatekeepers' (see e.g. Coddington \& Holton, 2014; Meraz \& Papacharissi, 2013; Singer, 2014; Thorson \& Wells, 2015) — have begun to influence how news is selected and disseminated, and the publishers themselves no longer enjoy the level of control they once had over how content is distributed. These new actors are typically large American technology companies that are sometimes reluctant to accept editorial responsibility for how news is filtered and consumed via their services. (Asked in August 2016 whether Facebook was in practice becoming a form of news editor, Mark Zuckerberg responded 'No, we are a tech company, not a media company.' ${ }^{1}$ ) In response to the questions that this shift raises, much research has focused on the role of ordinary media users - 'the people formerly known as the audience', in Jay Rosen's elegant phrase - in influencing the flow of information, especially on social media (see e.g. Messing \& Westwood, 2014; Bakshy, Messing, \& Adamic, 2015; Barberá, Jost, Nagler, Tucker, \& Bonneau, 2015). There has been much less work on the questions we focus on here: how people experience news on these platforms, how they think about the role of editorial selection in relation to algorithmic selection, and

\footnotetext{
${ }^{1}$ http://www.reuters.com/article/us-facebook-zuckerberg-idUSKCN1141WN (accessed February 23, 2017).
} 
how they understand the role of platforms themselves (see Hargittai, Neuman, \& Curry, 2012 for an exception). This is a clear shortcoming, as scholars have repeatedly underlined that the structural analysis of aggregated patterns of behaviour, networks, and the like must be accompanied by a similar attention to the ways in which people make sense of what José van Dijck (2013) calls "platformed sociality", including how they navigate news on social media.

In this paper, we present a mixed-methods comparative analysis of how people navigate news on social media, focusing specifically on attitudes towards selection by editors and journalists (editorial selection), and selection by algorithms on social networks (algorithmic selection). By combining focus group material and survey data, we find (i) that the majority of media users frequently do not understand how exactly the information they receive is filtered, but they do not uncritically accept it either, because they are sceptical of all forms of selection-including both editorial and algorithmic, (ii) that approval for algorithmic selection is stronger amongst younger people, and (iii) that those with a high level of interest in 'soft' news topics (and a low interest in 'hard' news topics) are more likely to approve of algorithmic selection on the basis of what their friends have consumed. We argue that the way in which most people navigate news on social media is thus based on a 'generalised scepticism' where people question all kinds of selection, including those they feel they have a relatively good understanding of (editorial selection by news organizations) and those that many of them have a much more limited understanding of (algorithmic selection by platform companies).

\section{Perceptions of news selection}

Traditionally, editors and journalists selected from countless pieces of available information to produce and publish a limited number of news items intended to help people understand the world around them (Shoemaker \& Vos, 2009). Long before the rise of social media, these 
news items were subjected to processes that, in effect, filtered them further. Consider, for example, the role of 'opinion leaders' in the two-step flow of communication (Katz \& Lazarsfeld, 1955). But many argue that digital media have made this second round of selection more important, as 'crowds' of ordinary users can elevate content to prominence online (e.g. Meraz \& Papacharissi, 2013) and 'user-generated visibility' influences the flow of news across newspaper websites ('most read stories', 'most shared stories', etc.) and social media platforms (by liking, commenting, and sharing, and thus influencing automated display decisions) (Singer, 2014).

To enable action at scale, social media platforms rely on algorithms to make automated display decisions about what content to show to which users, where algorithms are broadly defined as 'instructions for solving a problem or completing a task' (Pew, 2017a, p. 2). In this case, the task is the use of computational methods to sort and filter online information, of which news is just one of many possible categories. There is, of course, a vast technical literature on algorithms of this type that is beyond the scope of this paper. But there are also at least three possible starting points for considering algorithms within the context of social science: (i) a theoretical examination of the broad social, political and economic implications, (ii) empirical case studies of scenarios where algorithms have been employed, and the effects they had, and (iii) empirical research into how people experience algorithmic selection.

The first of these considers the broad social, political and economic implications of algorithms, predominantly using a theoretical approach (for an overview see Beer, 2017; Kitchin, 2017). The rationale for this research is the realization that algorithms increasingly make highly consequential decisions within society, and as such, are exercise considerable power (Beer, 2009). Though highly consequential, the inner workings of many of the most powerful algorithms are inaccessible, black boxed, or simply unintelligible (Pasquale, 2015). 
As such, researchers face difficulties in understanding how their power functions. Gillespie (2014) has argued that algorithms potentially constitute a new knowledge logic, based on 'the proceduralized choices of a machine, designed by human operators to automate some proxy of human judgment or unearth patterns across collected social traces'. This can be contrasted with the editorial logic that is based on 'the subjective choices of experts, themselves made and authorized through institutional processes of training and certification, or validated by the public through the mechanisms of the market'. When it comes to news, editorial selection is predominantly based on subjective choices made by professionals, whereas algorithmic selection is increasingly based on Gillespie's 'proceduralized choices'.

The second starting point focusses on how algorithms have been applied in specific situations, and the effect that this had. Within the context of journalism, much research has focused on how they are used by news organizations to help make decisions about what to put where on their websites (e.g. Anderson, 2011; Thurman, 2011). Building on Gillespie's (2014) distinction between algorithmic and editorial logics, DeVito (2016) used a content analysis of Facebook's own patents and press releases to derive the 'algorithmic values' used to inform news selection. In contrast to traditional news values based around 'novelty or oddity, conflict or controversy, interest, importance, impact or consequence, sensationalism, timeliness, and proximity' (Lee, 2009, p. 179 as cited in DeVito, 2016), DeVito identified 'friend relationships, explicitly expressed user interests, prior user engagement, implicitly expressed user preferences, post age, platform priorities, page relationships, negatively expressed preferences, and content quality' (DeVito, 2016, p. 1) as key to determining what news was likely to appear on a user's Facebook feed.

A much broader strand of research has aimed to understand the effect of algorithmic selection on exposure to information on social media. Most of this research is a response to fears that algorithmic selection will create more pronounced echo chambers (e.g. Sunstein, 
2017), or trap people inside filter bubbles (Pariser, 2011), because social networks use data on past behaviour to automatically show people more information on topics they are interested in, or on ideas they already agree with. Plausible though this may sound, a review of existing research conducted in 2016 concluded that there is not yet any empirical evidence that warrants any strong concern, partly because current technology does not appear to be responsive enough, and partly because people have always self-selected information in line with their interests and preferences (Zuiderveen Borgesius et al., 2016). Some studies have even shown that, in practice, algorithmic selection can expose people to more cross-cutting content, ultimately expanding and diversifying their information diets (Flaxman, Goel, \& Rao, 2016; Fletcher \& Nielsen, 2018). However, there remains the possibility that social networks also offer tools that enable more effective self-selection, perhaps increasing segregation and limiting cross-cutting exposure (e.g. Del Vicario, Zollo, Caldarelli, Scala, \& Quattrociocchi, 2017).

The third starting point considers how people experience algorithmic selection, and the extent to which people perceive the advantages and disadvantages. Some researchers have focussed on the possible advantages and disadvantages without making explicit reference to algorithmic selection. A recent study found that some US citizens have a "news-finds-me" perception, in part a result of algorithms that surface what their friends have shared on social media. People that feel this way are less likely to use traditional media, meaning that they can become less knowledgeable about politics and current affairs over time (Gil de Zúñiga, Weeks, \& Ardèvol-Abreu, 2017). This chimes with other research that has found that although there may be benefits associated with incidental exposure on social media in terms of civic and political participation (Valeriani \& Vaccari, 2016), there may be no positive effect on political learning (Bode, 2016). Whether people perceive these effects remains an open question. 
At present, we only have a very broad understanding of how people feel about algorithmic selection. Studies have considered general 'algorithmic awareness' (Bucher, 2017), or examined what we might call 'folk theories' of social media (Eslami et al., 2016). Eslami et al. (2015) found that a majority of Facebook users were not aware that their news feed was subject to algorithmic curation. They further found that although people sometimes felt that algorithmic selection is needed and appreciated, a lack of awareness can lead to dissatisfaction. In a follow-up, they found that people's satisfaction with algorithmic selection had either increased or stayed the same, suggesting increased awareness helps produce a more favourable view.

In a study of the way people experience algorithmic selection on Facebook (by what was then known the EdgeRank algorithm), Bucher (2012) drew on Foucault's Panopticon idea to describe how the news feed both made users visible to others, but simultaneously threatened them with invisibility. Building upon this, Bucher (2017) interviewed 25 people about their everyday experiences with Facebook's news feed. Interviewees spoke of a range of experiences - some positive, some negative - meaning that 'the lived reality of the Facebook algorithm generates a plethora of ordinary affects from the frustration of not getting any "likes" to the strange sensation of thinking "who are these people who suddenly show up"?' (Bucher, 2017, p. 42). Concerning news, one interviewee described how she only thought about Facebook's algorithm when it served up news poorly aligned with her interests and beliefs. Of course, the flip side of this view is that when the algorithm performs as expected, it goes unnoticed, eliciting neither a positive nor negative reaction.

In summary, there is a growing literature on the use of social media as a news source, and on algorithms within the social sciences, including recent research that has aimed to uncover how people experience algorithms and how they feel about them. But there is little research focused specifically on how people navigate news on social media (as opposed to 
the wider array of information available), including how they think about the relationship between editorial and algorithmic selection. These are the questions we focus on here.

\section{Qualitative data}

For the inductive, qualitative stage, we rely on focus group material, because the focus group method provides a flexible and open-ended way of exploring people's perceptions and interpretations of the world (e.g. Lunt \& Livingstone, 1996). Focus groups are particularly useful for identifying unanticipated responses and for exploring a range of different views, and for producing inductive findings that can in turn help articulate hypotheses that can be tested using quantitative data.

Working with a market research company and with local academic partners, we conducted 8 focus groups across Germany, Spain, the UK, and the US in February 2016. The groups were run by professional moderators and observed by one of the authors or by local academic partners. All focus groups were the same length, and although they were conducted in different languages (in Spain and Germany), the moderators worked from a common discussion guide that was written by the authors. Participants were asked to complete a range of pre-tasks to sensitise them to their actual news habits and encourage them to reflect on them in advance of the discussion. The pre-task included a news diary to build participants' awareness of news stories they had followed, and the sources, platforms and devices used. In addition, a deprivation exercise required participants to live without digital news sources for a day to help uncover their role by disrupting often-habitual behaviours.

In each country, we organised one focus group of online news users aged between 20 and 34, and one focus group with participants between 35 and 54. We structured conversations around relatively similar age groups with an even gender mix to encourage positive group dynamics, and deliberately avoided both the youngest and the oldest media 
users, as these have demonstrably different media habits (Newman et al., 2016). Participants were also recruited to achieve a mix of mid- to high social grade, mid- to high levels of interest in news, as well as a range of political views. All were internet users, all use smartphones, and all use digital news. There were 56 participants in total. The groups were not meant to be representative in a statistical sense, but to represent a wide range of different perspectives on digital news. Each session was recorded and transcribed, and the transcripts from Germany and Spain were translated into English.

\section{Inductive focus group analysis}

The focus group material was subjected to an open-ended, inductive analysis. Transcripts were read and coded across countries and age groups, first using an open coding of the entire material, followed by a second round of focused coding oriented at understanding how participants say that they navigate news on social media (Charmaz, 2006). What we present here is not an exhaustive or comprehensive analysis of the much wider discussions, but focused specifically on how people navigate news on social media. As the qualitative data did not suggest significant national differences, we present the analysis in terms of themes rather than by country. In using the focus group material, we have chosen to use longer quotations which sometimes include exchanges with moderators and other participants where useful. We have tried to give a sense of the full texture of the transcripts, which sometimes include stray thoughts, asides, and other layers of information. We hope that this retains a high fidelity to how participants speak and thus enable the reader to hear what participants say in their own voices.

First, our focus group participants encounter news on social media with a clear definition of news (as distinct from 'information', or 'content', or things that are 'new to me') that is closely tied to conventional forms of professional journalism. 'News,' says one 
participant, 'is produced. They don't just give you the raw feed' (US, 35-54). It is 'bundled information about current affairs' as one German respondent says (20-34). In the focus group discussions, many participants appreciate professional journalists' ambition to be relatively impartial and objective in their reporting, but were also very critical of perceived bias in news, of the impact of many news organizations' commercial imperatives, and other factors like the influence of political elites or media proprietors. Many do not have a great deal of trust in the news media.

Second, most of our focus group participants say that they do come across news (generally seen as professionally produced news) on social media. This exchange from one of the UK groups (35-54) is indicative of the process of incidental exposure (Fletcher \& Nielsen, 2018):

Participant 1 : For me it feels like [it's] just not somewhere I'd want to be getting news. I'm not on social media for news. Not for like news. Like maybe like new from like around my social circle.

Moderator: Okay, so it might not be a place, like a destination to get news but would you pick things up perhaps ...

$\mathrm{P}_{1}$ : You pick it up.

$\mathrm{P}_{2}$ : You do pick it up.

$\mathrm{P}_{3}$ : You pick it up for sure, yes.

Moderator: And some of you were saying it's ...

$\mathrm{P}_{4}$ : You find stuff you might not find elsewhere.

Younger respondents elsewhere described similar experiences. 'I'm on Facebook anyway when I'm bored. Get my smartphone out on the bus or at home. I just scroll there and I'm sort of accidentally informed and I like that' (Germany, 20-34), or in even stronger language from Spain 'We don't look for news on Facebook. They throw it at us.' (20-34). 
Third, building off their identification of what constitutes 'news' specifically, most focus group participants clearly recognised that social networks like Facebook are not themselves sources of news. A recent study in the US found that 10 percent of survey respondents identified 'Facebook' as a news outlet (Pew, 2017b). This did not happen in any of our 8 focus groups. Instead, people see news as originating with news organizations, even when they come across it on social media.

Participant 1 : They're fed by the online news. A friend sees the story and shares it.

Moderator: Social media is fed by online news?

$\mathrm{P}_{1}$ : Yes.

$\mathrm{P}_{2}: 80 / 90 \%$ of it, yes. (Spain, 35-54).

Explicitly engaging with a combination of different kinds of news selection, one of the younger German participants put it like this:

I wouldn't say I believe Facebook more than other media. I know where I'm getting myself informed and I read everything. But I wouldn't say... "wow, Facebook. I'm all for it”. [...] Because it's not Facebook that's behind each piece of news. That might be Spiegel, Zeit, Süddeutsche. [...] It's only a platform... things are spread and shared. (20-34)

One of the older respondents in the UK put the point differently. 'Facebook itself is just a database. Your login details will bring you your page. The rest of it is a number of platforms from a number of different sources all linked and brought in.' (UK, 35-54).

It is important to recognise that participants show varying degrees of awareness of how social media actually filter news content. Take this exchange from the focus group with younger people in Spain (20-34): 
Participant: Well, I've never thought about it.

$\mathrm{P}_{2}$ : Me neither.

$\mathrm{P}_{1}$ : Supposedly they do, because all media want to publish everything.

$\mathrm{P}_{3}$ : I think all media might be on there, because it's free.

A limited awareness of algorithmic filtering was also found in the US and the UK. 'I haven't seen that before. What, you mean like they select stories you want to read?' (UK, 20-34).

'Moderator: how does it choose which news brand to provide for that particular story?

Participant: That's a good question. I don't know how they do it.' (US, 34-54).

Some participants do have a fairly clear, but basic view of how they think social media platforms filter content; what Eslami et al. (2016) call 'folk theories' of social feeds. 'Based on things you like and your browsing history' (US, 20-34), 'Facebook lives on things that I feed Facebook with. It's put together based on my interests, likes, and activities' (Germany, 20-34). Importantly, and irrespective the level of explicit understanding of algorithmic filtering people display, we did not have a single participant expressing a view like the 'I just trust Google' stance identified by Hargittai et al. (2012) on the basis of their 2009 focus groups in the US. None of our participants displayed this kind of naïve confidence in algorithms or platforms. Nor did they express the idea that because they have low trust in editorial selection (or journalism and the news media as a whole), that this should translate, or has translated, into approval for algorithmic selection.

A few quotes can illustrate the different ways in which people compare the two types of selection. On some occasions, participants display a measured approach that recognises that there are 'pros and cons to [social media] just like any news source' (US, 20-34):

I like that people are accountable. [Editors] are accountable. The computer's not accountable. [But] I love the idea that computers can personalise my individual tastes and Facebook does that with subscriptions. So you personalise what you want to come to you and I like that. (UK, 35-54). 
But in some cases, participants within groups have the same broad reservations about both. One of the US groups discussed the political bias that influences editorial selection. As one participant explained, 'when it comes to politics like the election I stay away from Fox News [...] I guess it's generally accepted that it's all one-sided' (US, 20-34). Then later, when the group was asked to sum up news on social media in one word, after considering that much of the news they see is posted by people they know, someone suggested 'biased', with another agreeing that 'yeah, biased is a good word'. (US, 20-34). Consider another example from the UK, where there was a general concern over sensationalism and prioritising certain news stories to generate clicks. In talking about TV news one participant said 'I get frustrated sometimes, when the main headline story is something that [it] shouldn't be', and that news websites 'have very sensationalist topics to generate hits' (UK, 20-34). However, they also recognise that algorithmic on social media can produce similar results:

Participant 1 : Some stories can just get sensationalised and out of proportion, I think, and other stories ignored.

$\mathrm{P}_{2}$ : Things are taken out of context a lot as well.

$\mathrm{P}_{1}$ : Yes. (UK, 20-34).

These quotes capture a widespread form of generalised scepticism where people use different sources and platforms for different purposes without having naïve confidence in any one of them. People thus tend to operate with a distinction between editorial selection (of which they have a mixed view, and frequently do not trust very much) and algorithmic selection (which they display different degrees of understanding of). Most approach both with what we would describe as 'generalised scepticism'.

One notable difference across the qualitative material was a difference between older and younger media users in terms of how they talked about algorithmic filtering. Generally, it 
was discussed more frequently, and in more detail, in the focus groups with younger people. Of course, some older participants had views on how social media select news. 'You don't have to search for news. The news is put together according to what the algorithm thinks I might be interested in' (Germany, 35-54). But younger media users, though not the omnipresent and omnipotent 'digital natives' some have fantasised about, more frequently talk about the ways in which they proactively influence what news they see on social media by picking sources and adjusting settings.

You are essentially the editor aren't you. Because you just select your sources, generally speaking. (UK, 20-34).

I'm going to these sites to be social with my friends, not to look at the articles they're posting. A lot of times I'll actually block seeing people from my newsfeed on Facebook if they're posting things that are just completely inaccurate all the time. [...] I don't want to get my news from any of these sources. (US, 20-34).

Older media users are sometimes aware that social media rely on algorithmic filtering, but they very rarely bring up their own agency, and when asked about it sometimes simply say they do not know how to exercise it. Some are not aware that these options to influence the algorithmic filters exist. 'Moderator: But on Facebook you've got the option to say, I'd like to have this and that? Participant: I'd not know how to do that on Facebook. I don't think Facebook does that.' (Germany, 35-54).

Finally, many people - both young and old - explicitly differentiate social media as a source of relatively 'soft' news. One of the younger focus group participants in Spain said: '[Social media] is where I see more international and bizarre stories. You click because you say, "Look at that, how funny!" Or because you simply don't believe it and you click because you say, "How strange!"” (Spain, 20-34). An older participant from the UK expressed a 
similar view: 'I often see like trending stuff and it's quite celebrity, gossipy and it's just not really, well, it's not really the news that I want to see but sometimes I'm totally sucked in.' (UK, 35-54). One US participant makes the soft-hard distinction very explicitly:

If I'm going through a social media site it's for more frivolous entertainment stuff. Not for real hard news stuff. And I don't care what other people are, you know, what friends or anyone else's opinion is. If I'm interested I'm going to get the facts on my own. (US, 35-54).

\section{Deductive hypotheses}

We now move from the inductive qualitative analysis to our deductive quantitative analysis, where we test three hypotheses developed on the basis of our focus group material, as well as the existing research discussed above. The focus groups provide a valuable source of evidence for better understanding how people think about navigating news on social media, and give some indications of possible differences between people with different attitudes towards news, between different age groups, and between people with an appetite for different kinds of news.

First, our focus group participants, while often making an explicit distinction between editorial and algorithmic selection, typically approached both on the basis of various degrees of 'generalised scepticism'. Participants did not see algorithmic selection as a way of sidestepping editorial selection. We therefore expect approval for editorial selection to be positively associated with approval for algorithmic selection, rather than disapproval of one informing approval of the other (a negative association).

H1: People who think that editorial selection is a good method of news selection are more likely to think that algorithmic selection is a good method of news selection. 
Second, because participants in the younger focus group often demonstrated both a more developed and explicit 'algorithmic awareness', more favourable attitudes towards platforms, and talked more explicitly about how they exercised agency to influence how social media served them news, we expect a negative association between age and approval for algorithmic selection.

H2: Younger people are more likely to approve of algorithmic selection.

Third, because the focus group participants, regardless of age, expressed the view that they felt more comfortable with news being selected by algorithms if it was about less-serious or 'soft' news topics, but potentially concerned about the use of algorithmic selection for news about 'hard' news topics, we expect a positive association between levels of interest in soft news topics, and approval for algorithmic selection. Relatedly, we also expect a negative association between interest in hard news topics and approval for algorithmic selection.

H3: People more interested in soft news topics are more likely to approve of algorithmic selection.

\section{Quantitative data}

Our survey data comes from the 2016 Reuters Institute Digital News Report (Newman et al., 2016). The survey was conducted by YouGov in partnership with the Reuters Institute at the University of Oxford during late January and early February 2016. An online questionnaire was used to survey over 50,000 respondents across a total of 26 countries. Samples were drawn from panels within each country, and respondents were invited to complete the survey in order to meet quotas based on age, gender, and region. Samples were then weighted according to census data or industry-accepted targets to match the national population. 
Respondents who said that they used news less than once a month were filtered out at an early stage.

The data have several key strengths. First, the survey contained an extensive list of questions that capture news media use across platforms, in addition to data on attitudes to news (interest in news, trust in news, etc.). Key demographic data is also collected, allowing us to control for a range of different factors when conducting the analysis. Second, the survey captured data using the same questions at the same point in time across a range of different countries, thus affording a comparative analysis. Here, we will use the data from the same four countries in order to align with the focus group stage.

The data have some limitations that need to be kept in mind. First, it is drawn from an online panel, and as a result, the observations do not constitute a random sample, and will under-represent the views of the minority within each country who are not online. Also, as the data are cross-sectional, we are able to identify associations between variables, but not causation. Though we attempted to ensure that the questions on news selection were as clear as possible (see next section), it is possible that some respondents misunderstood what the question was asking about. Despite these limitations, we believe that surveys are the only reliable way of determining the attitudes and opinions that are broadly representative of a national population, thus complementing the more detailed data from the focus group sessions.

\section{Dependent variables}

We focus on two dependent variables that each refer to a different type of algorithmic selection: (i) approval for algorithmic selection based on personal consumption, and (ii) approval for algorithmic selection based on social recommendations. The two are not, in fact, necessarily entirely distinct in practice, as different platforms filter content in different ways 
based on multiple factors. But because of the highly-varying levels of algorithmic awareness and often limited familiarity with technical language and distinctions, we phrased the survey questions in terms intended to be intelligible for most respondents. (The questions were user tested in advance of fielding the survey.) Both questions were asked about in similar ways. We asked respondents to indicate their level of agreement (on a five-point scale ranging from strongly agree to strongly disagree) with the following statements (i) 'having stories automatically selected for me on the basis of what I have consumed in the past is a good way to get news', and (ii) 'having stories automatically selected for me on the basis of what my friends have consumed is a good way to get news'. In an attempt to improve data quality, and given that many respondents likely had a limited understanding of news production, we wanted to make clear that all news has to be selected in some sense. We therefore prefixed these questions with the following explanatory statement: 'Every news website, mobile app or social network makes decisions about what content to show to you. These decisions can be made by editors and journalists or by computer algorithms analysing information about what other content you have used, or on the basis of what you and your friends share and interact with on social media'. Responses were numerically recoded to range from one to five.

\section{Independent variables}

In light of our hypotheses, we focus on three independent variables: (i) approval for editorial selection, (ii) age (in years), and (iii) interest in soft/hard news. Approval for editorial selection was asked about in a very similar way to approval for algorithmic selection. The exact statement used was 'having stories selected for me by editors and journalists is a good way to get news'. This question was also prefixed with the explanatory statement from the previous subsection. 
The age of each respondent was not asked during the survey itself, but was instead drawn from YouGov's data on each member of their online panel submitted during registration. YouGov periodically verify this data, and all resulting discrepancies are investigated.

The measure of interest in soft/hard news was computed using a total of eight questions. The questions asked the respondent to indicate their level of interest in various news topics on a five-point scale ranging from not at all interested to extremely interested. After the data were from these questions were numerically recoded, the level of interest in soft news was based on the mean level of interest in the following four topics: entertainment and celebrity news, lifestyle news, arts and culture news, and sports news. Level of interest in hard news was computed in the same way, but using the following topics: international news, political news, business and economic news, and health or education news.

We also use a series of control variables based on individual-level data on gender, left/right political ideology, education, trust in news, and frequency of internet use. Trust in news (recorded on a five-point scale) and frequency of internet use (recorded on an eightpoint scale) are treated as continuous. Gender, education, and political ideology are treated as categorical. Education has three categories: currently in education, educated up to school level, and educated past school level (which includes a significant number of people who say they have professional qualifications). As around $10-15 \%$ in each country indicated 'don't know' to the question on political ideology, we include this as a category to avoid excluding cases. The much smaller number of people who responded with 'don't know' to any of the other questions were removed.

Table 1. Descriptive statistics

UK US Germany Spain




\begin{tabular}{|c|c|c|c|c|}
\hline Editorial selection & 2.62 & 2.62 & 3.05 & 2.84 \\
\hline & $(.99)$ & $(1.09)$ & $(1.04)$ & $(1.18)$ \\
\hline Algorithmic selection based & 2.81 & 2.96 & 3.04 & 3.05 \\
\hline on personal behaviour & $(1.08)$ & $(1.13)$ & $(1.04)$ & $(1.15)$ \\
\hline Algorithmic selection based & 2.32 & 2.45 & 2.73 & 2.61 \\
\hline on social recommendations & $(1.01)$ & $(1.09)$ & $(1.06)$ & $(1.15)$ \\
\hline \multirow[t]{2}{*}{ Age } & 47.13 & 46.73 & 47.40 & 45.47 \\
\hline & $(16.53)$ & $(17.47)$ & $(15.69)$ & $(14.57)$ \\
\hline \multirow[t]{2}{*}{ Interest in hard news } & 3.35 & 3.47 & 3.55 & 3.69 \\
\hline & $(.72)$ & $(.80)$ & $(.74)$ & $(.71)$ \\
\hline \multirow[t]{2}{*}{ Interest in soft news } & 2.66 & 2.66 & 2.85 & 3.00 \\
\hline & $(.74)$ & $(.86)$ & $(.78)$ & $(.70)$ \\
\hline Gender (Female) & $51.9 \%$ & $50.57 \%$ & $51.51 \%$ & $51.06 \%$ \\
\hline \multicolumn{5}{|l|}{ Political ideology } \\
\hline Left & $21.91 \%$ & $21.9 \%$ & $7.44 \%$ & $29.82 \%$ \\
\hline Right & $48.63 \%$ & $40.33 \%$ & $72.62 \%$ & $53.52 \%$ \\
\hline Centre & $15.07 \%$ & $24.36 \%$ & $3.24 \%$ & $7.52 \%$ \\
\hline Don't know & $15.39 \%$ & $13.4 \%$ & $16.71 \%$ & $9.14 \%$ \\
\hline \multicolumn{5}{|l|}{ Education } \\
\hline In education & $3.91 \%$ & $8.11 \%$ & $1.79 \%$ & $3.49 \%$ \\
\hline School & $46.46 \%$ & $51.15 \%$ & $28.59 \%$ & $29.03 \%$ \\
\hline Further/professional & $49.63 \%$ & $40.73 \%$ & $69.62 \%$ & $67.47 \%$ \\
\hline \multirow[t]{2}{*}{ Trust } & 3.30 & 2.86 & 3.35 & 3.20 \\
\hline & $(.91)$ & $(1.08)$ & $(.96)$ & $(1.08)$ \\
\hline \multirow[t]{2}{*}{ Frequency of internet use } & 6.69 & 6.61 & 6.63 & 6.73 \\
\hline & $(1.23)$ & $(1.25)$ & $(1.18)$ & $(1.06)$ \\
\hline
\end{tabular}


Note. Unless otherwise indicated columns showing mean followed by standard deviation in parentheses.

\section{Results}

\section{Descriptive statistics}

Table 1 contains descriptive statistics for all variables used in the analysis. We can see at a glance that everywhere apart from Germany, approval for algorithmic selection based on personal behaviour is on average higher than approval for editorial selection. In every country, approval for editorial selection is higher than for approval for algorithmic selection based on social recommendations. Approval for all types of selection is generally low, on average below the midpoint of 3.00 in most cases.

We can also briefly consider the relationship between editorial and algorithmic selection. Figure 1 is a heatmap showing the number of people in each country who responded in each way to the questions on primary and secondary gatekeeping. At a glance, we can see that most people hold a similar (and often low) level of approval for each type of gatekeeping because the shading is darker along the left to right upwards diagonal. Only a relatively small number of people have high approval for editorial selection, say, and a low level of approval for algorithmic selection based on personal behaviour. Rather, people who think that editorial selection is not a particularly good way of getting the news also tend to think that algorithmic selection is not a particularly good way either.

Figure 1. Heatmap showing relationship between approval for editorial and algorithmic selection 


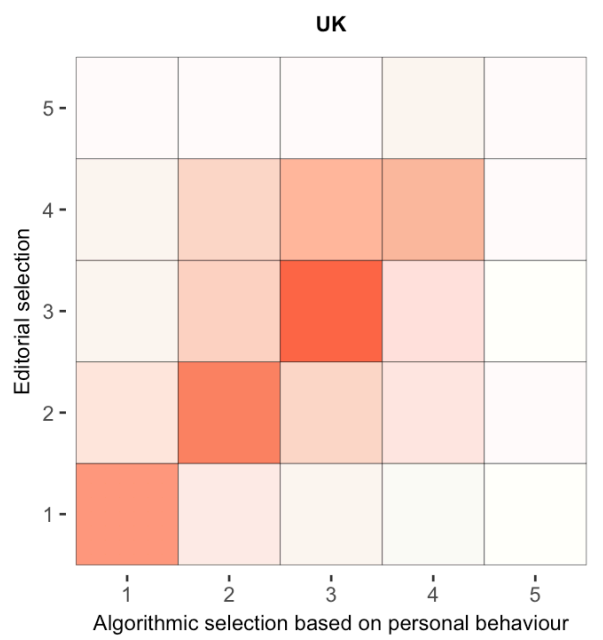

US

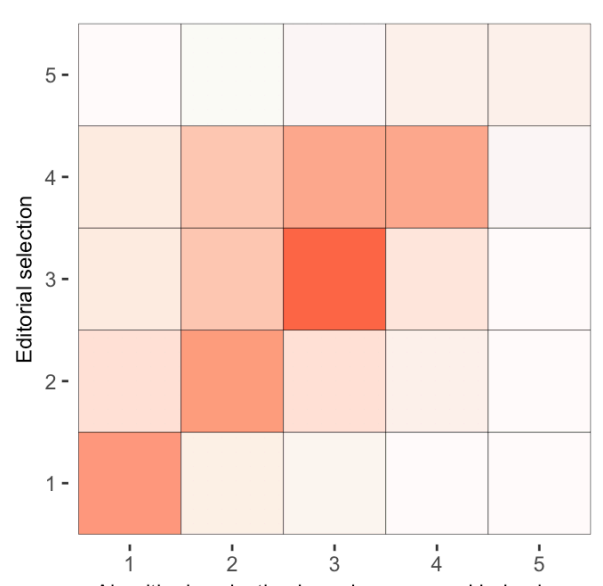

Algorithmic selection based on personal behaviour

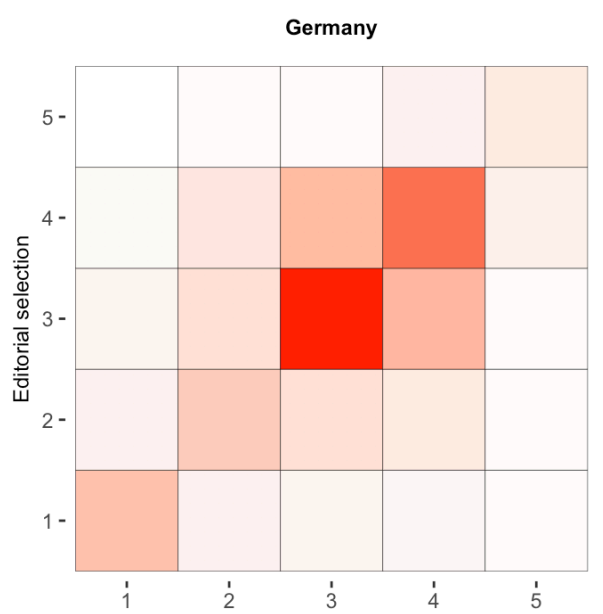

Algorithmic selection based on personal behaviour

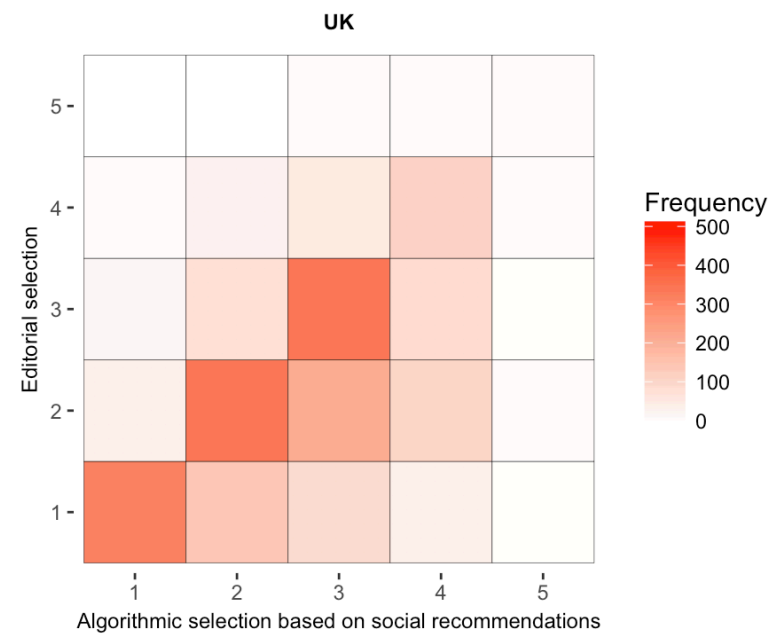

US

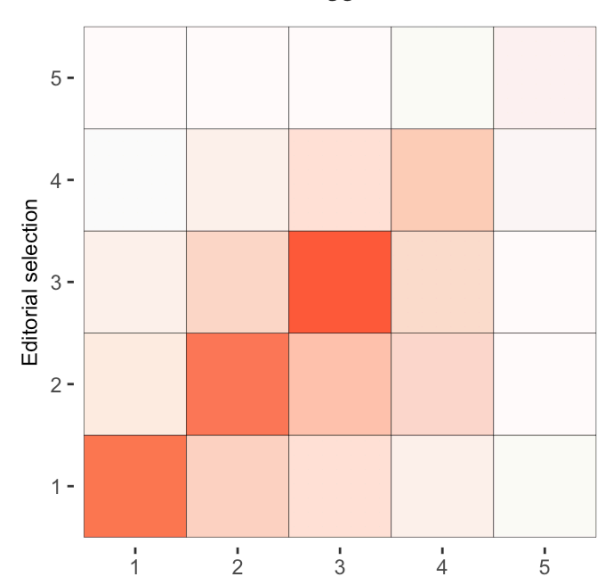

Frequency

Frequency

500
400
-300
200
100
0

Algorithmic selection based on social recommendations

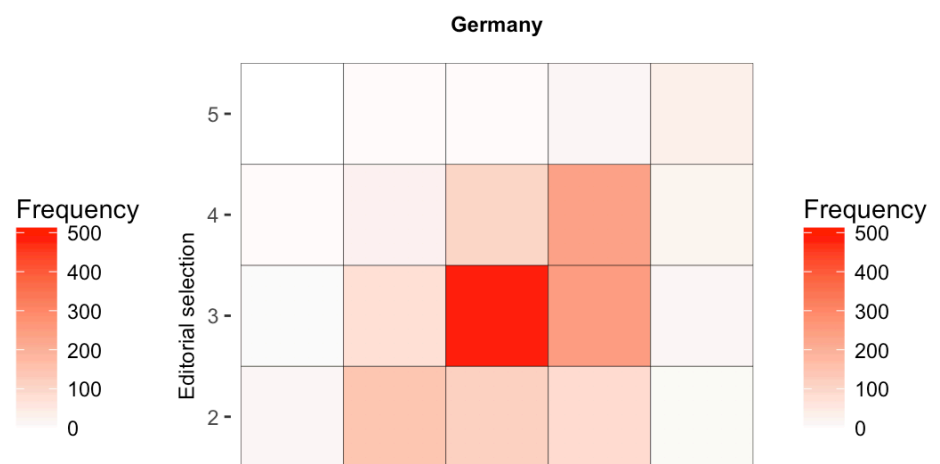



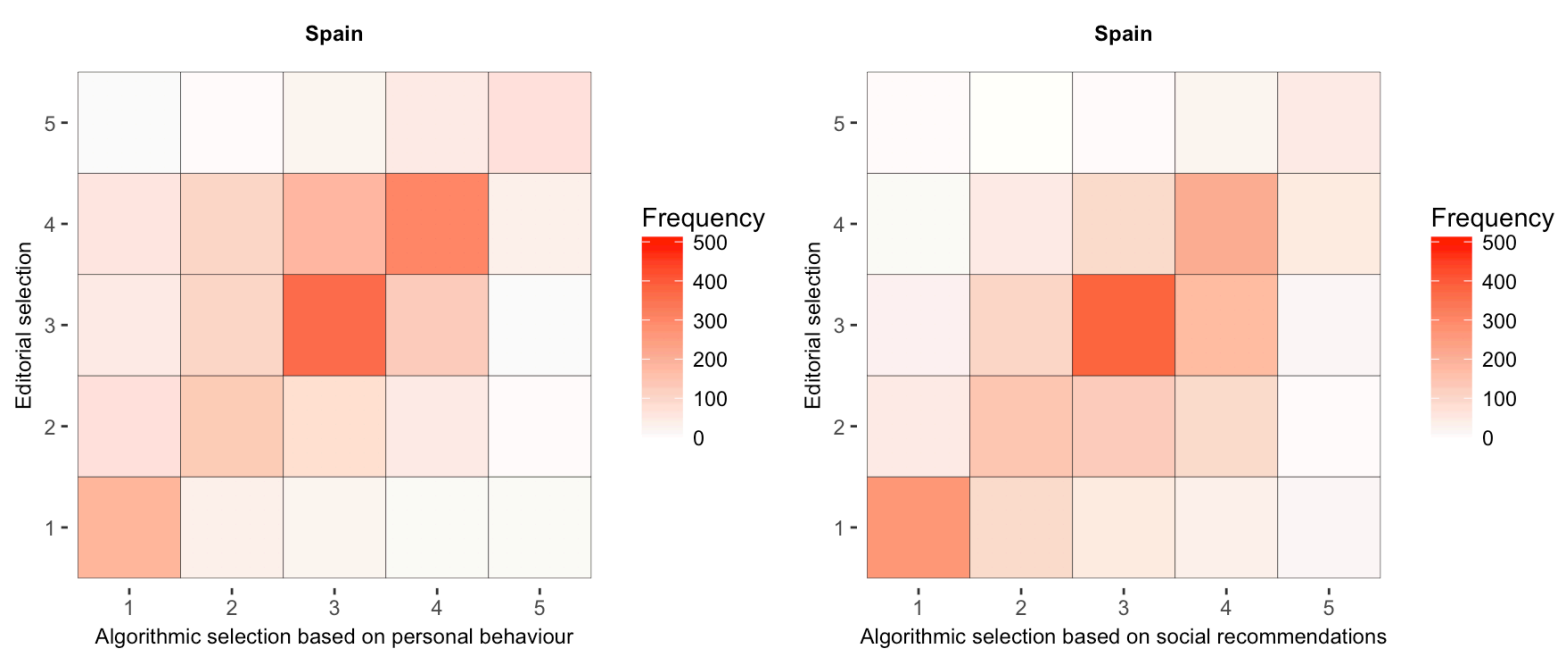

\section{Hypothesis testing}

We use a series of ordinary least squares regression models to test for the association between each independent variable and approval for both types of algorithmic selection. All noncategorical variables were standardised according to the procedure defined by Gelman (2008) in order to make the coefficients more easily comparable. We have produced a separate model for each type of algorithmic selection within each country, resulting in eight models.

Table 2 summarises models for each country where the dependent variable is approval for algorithmic selection based on personal behaviour. Hypothesis 1 predicted a positive association between this and approval for editorial selection. We can see that in every country there is indeed a strong positive association. Hypothesis 2 predicted a negative association between age and algorithmic selection based on personal behaviour. This is the case in every country other than Germany, where the association is negative but not significant. Hypothesis 3 predicted a positive association between approval for algorithmic selection based on personal behaviour and interest in soft news, and a negative association with interest in hard news. However, in most countries we do not find any evidence to support this. Again, the exception is Germany, where those more interested in soft news are more likely approve of algorithmic selection based on personal behaviour. These associations 
are present as we simultaneously control for gender, political ideology, education, trust in news, and frequency of internet use. Although much of the variance is explained by approval for editorial selection (and therefore news selection in general), age remains a significant factor.

Table 2. OLS regression where the dependent variable is approval for algorithmic selection based on personal behaviour

\begin{tabular}{ccccc} 
& UK & US & Germany & Spain \\
\hline Editorial selection & $1.17^{* * *}$ & $1.17^{* * *}$ & $1.22 * * *$ & $1.14 * * *$ \\
Age & $(.04)$ & $(.05)$ & $(.04)$ & $(.04)$ \\
Interest in soft news & $-.35 * * *$ & $-.34 * * *$ & -.05 & $-.24 * * *$ \\
& $(.05)$ & $(.05)$ & $(.04)$ & $(.05)$ \\
Interest in hard news & .06 & .05 & $.16^{* * *}$ & .08 \\
& $(.04)$ & $(.05)$ & $(.04)$ & $(.05)$ \\
& -.08 & .02 & -.01 & $.10 *$ \\
Gender (female) & $(.04)$ & $(.05)$ & $(.05)$ & $(.05)$ \\
& -.07 & .01 & -.03 & .03 \\
& $(.04)$ & $(.04)$ & $(.04)$ & $(.04)$
\end{tabular}

Political ideology (centre)

$\begin{array}{lcccc}\text { Left } & .01 & .02 & .07 & -.06 \\ & (.05) & (.06) & (.07) & (.05) \\ \text { Right } & .02 & .15 * * & .12 & -.05 \\ & (.06) & (.05) & (.11) & (.08) \\ \text { Don't know } & -.01 & -.05 & .00 & -.20 * \\ & (.07) & (.07) & (.06) & (.08)\end{array}$

Education (in education) 
Further

.06

.01

$-.24$

$-.05$

Trust in news

.05

$.09 *$

.04

$.13 * *$

Internet frequency

$.10 *$

.08

.02

$.09 *$

(.04)

(.04)

(.04)

(.04)

Constant

$2.59 * * *$

$2.80 * * *$

$3.26 * * *$

$3.12 * * *$

$$
\mathrm{R}^{2}
$$

.37

.33

.38

$\mathrm{N}$

1986

2098

1944

2055

$* \mathrm{p}<.05,{ }^{* *} \mathrm{p}<.01, * * * \mathrm{p}<.001$. Note. columns showing standardised regression coefficients followed by standard error in parentheses.

Table 3 summarises the models where the dependent variable is approval for algorithmic selection based on social recommendations. Here, we see a significant association in every country between this and approval for editorial selection. Based on this, and data from the previous subsection, we can say that hypothesis 1 is supported. Again, we see that age is significantly and negatively associated in every country other than Germany. Hypothesis 2 is therefore largely supported. In contrast to the models in Table 2, interest in soft news is positively associated with approval for algorithmic selection based on social recommendations, and interest in hard news is negatively associated everywhere other than the UK. Put differently, those more interested in soft news are more likely to approve of algorithmic selection based on social recommendations, but no more likely to approve of algorithmic selection based on past behaviour. Hypothesis 3 is therefore supported, but only for one type of algorithmic selection. Again, age and interest in soft news account for some of the variance, but most is explained by approval for editorial selection. 
Table 3. OLS regression where the dependent variable is approval for algorithmic selection based on social recommendations

\begin{tabular}{ccccc} 
& UK & US & Germany & Spain \\
\hline Editorial selection & $.98 * * *$ & $1.04 * * *$ & $1.14 * * *$ & $1.15 * * *$ \\
Age & $(.04)$ & $(.04)$ & $(.04)$ & $(.04)$ \\
Interest in soft news & $-.32 * * *$ & $-.32 * * *$ & -.03 & $-.25 * * *$ \\
& $. .04)$ & $(.04)$ & $(.04)$ & $(.05)$ \\
Interest in hard news & $(.04)$ & $.27 * * *$ & $.39 * * *$ & $.34 * * *$ \\
& -.07 & $-.12 * *$ & $-.11 *$ & $(.04)$ \\
\hline Gender (female) & $(.04)$ & $(.04)$ & $(.05)$ & $(.05)$ \\
& -.02 & -.06 & .01 & $-.12 * *$ \\
& $(.04)$ & $(.04)$ & $(.04)$ & $(.04)$
\end{tabular}

Political ideology (centre)

$\begin{array}{lcccc}\text { Left } & .02 & -.13 * * & -.02 & .00 \\ \text { Right } & (.05) & (.05) & (.08) & (.05) \\ & -.01 & .10 * & .17 & .07 \\ \text { Don't know } & (.01) & (.05) & (.11) & (.08) \\ & .20 * * & .09 & .09 & .04 \\ & (.06) & (.07) & (.06) & (.08)\end{array}$

Education (in education)

$\begin{array}{lcccc}\text { School } & .11 & .01 & -.17 & -.10 \\ & (.11) & (.09) & (.16) & (.13) \\ \text { Further } & .04 & -.11 & -.26 & -.05 \\ & (.11) & (.09) & (.16) & (.12) \\ \text { Trust in news } & -.05 & .10 * & -.11 * * & .17 * * *\end{array}$


$\mathrm{R}^{2}$

1986

${ }^{*} \mathrm{p}<.05,{ }^{* *} \mathrm{p}<.01,{ }^{* * *} \mathrm{p}<.001$. Note. columns showing standardised regression coefficients followed by standard error in parentheses.

\section{Discussion}

We have examined how people navigate news on social media and how they perceive the different kinds of news selection they encounter there. On the basis of an inductive analysis of focus group material, we have argued that most people operate with a distinction between news organisations (actors that use editorial selection to produce the kinds of content socially recognised as 'the news') and platforms like social media where many get news but that are not seen as news sources in themselves (and are hence actors that filter content produced by others). We find that many of our focus group participants navigate news on social media with 'generalised scepticism' - they frequently do not understand precisely how the information they receive is filtered, but they do not accept it uncritically either. Based on our focus groups and existing research on 'algorithmic awareness' (Bucher, 2017) and 'folk theories' of social media (Eslami et al., 2016), we developed a set of specific hypotheses about people's different perceptions of various kinds of news selection. Building on this inductive analysis, we in turn test these with quantitative survey data from Germany, Spain, the UK, and the US. We find support for the idea (i) that the majority of media users approach news selection online with a 'generalised scepticism' and are sceptical of all kinds 
selection, (ii) that approval for algorithmic selection is stronger amongst younger people, and (iii) that those with a high level of interest in 'soft' news topics (and a low interest in hard news topics) are more comfortable with algorithmic filtering of news content on the basis of what their friends have consumed. In both the qualitative and the quantitative analysis, the cross-country differences were less salient than differences associated with attitudes to news, age, and interest. Both the qualitative and the quantitative findings are consistent across the countries covered.

The kinds of generalised scepticism identified here provide an important corrective to the fear that people, while potentially aware and often critical of how editorial selection functions, have a naïve confidence in how the algorithmic filters deployed by various platform companies work. None of our focus group participants expressed the kind of 'I just trust Google' stance identified by Hargittai et al. (2012), and our survey data too suggest that limited numbers of people see algorithmic filtering as an unproblematic way of getting news, or as an alternative to editorial selection. For those interested in understanding different "user tactics" (van Dijck 2013, p. 20), this combination of inductive and deductive work, qualitative and quantitative analysis, offers important new insights into how people navigate news in platformed environments.

Of course, the fact that social media are an increasingly widely-used and important source of (accessing and finding) news, even as people remain sceptical of how they filter news, suggests a possible paradox. Why do we use these platforms if we are sceptical of how they work? Perhaps the kind of combination of intellectual scepticism and day-to-day pragmatism that has long characterised many digital media users' approaches to privacy is instructive here. In complex societies, we all rely on many systems and technologies that we use without necessarily understanding or trusting them (Pasquale, 2015), because they enable and help us in ways we find compelling. When it comes to algorithmic filtering, which is 
becoming a more important for how more and more people get news, perhaps the next step is to hope we can move from generalised scepticism to informed scepticism with a better understanding of the basic ways in which platforms filter content.

\section{References}

Anderson, C. W. (2011). Deliberative, Agnostic, and Algorithmic Audiences: Journalism's Vision of its Public in an Age of Audience Transparency. International Journal of Communication, 5, 529-547.

Bakshy, E., Messing, S., \& Adamic, L. A. (2015). Exposure to ideologically diverse news and opinion on Facebook. Science, 348, 1130-1132.

Barberá, P., Jost, J. T., Nagler, J., Tucker, J. A., \& Bonneau, R. (2015). Tweeting from Left to Right: Is Online Political Communication More Than An Echo Chamber. Psychological Science, 26, 1531-1542.

Beer, D. (2009). Power Through the Algorithm? Participatory Web Cultures and the Technological Unconscious. New Media \& Society, 11(6), 985-1002.

Beer, D. (2017). The Social Power of Algorithms. Information, Communication \& Society, $20(1), 1-13$.

Bode, L. (2016). Political news in the news feed: Leaning politics from social media. Mass Communication and Society, 19(1), 24-48. https://doi.org/10.1080/15205436.2015.1045149

Bucher, T. (2012). Want To Be On the Top? Algorithmic Power and the Threat of Invisibility on Facebook. New Media \& Society, 14(7), 1164-1180.

Bucher, T. (2017). The Algorithmic Imaginary: Exploring the Ordinary Affects of Facebook Algorithms. Information, Communication \& Society, 20(1), 30-44. 
Charmaz, K. (2006). Constructing Grounded Theory: A Practical Guide Through Qualitative Analysis. New York, NY: SAGE.

Coddington, M., \& Holton, A. E. (2014). When the Gates Swing Open: Examining Gatekeeping in a Social Media Setting. Mass Communication and Society, 17(2), $236-257$.

Del Vicario, M., Zollo, F., Caldarelli, G., Scala, A., \& Quattrociocchi, W. (2017). Mapping Social Dynamics on Facebook: The Brexit Debate. Social Networks, 50, 6-16.

DeVito, M. A. (2016). From Editors to Algorithms: A Values-based Approach to Understanding Story Selection in the Facebook News Feed. Digital Journalism, O(0), $1-21$.

Eslami, M., Karahalios, K., Sandvig, C., Vaccaro, K., Rickman, A., Hamilton, K., \& Kirlik, A. (2016). First I "Like" it, then I Hide it: Folk Theories of Social Feeds. In Proceedings of the 2016 CHI Conference on Human Factors in Computing Systems (pp. 2371-2383). New York, NY: ACM.

Eslami, M., Rickman, A., Vaccaro, K., Aleyasen, A., Vuong, A., Karahalios, K., ... Sandvig, C. (2015). "I Always Assumed that I Wasn't Really that Close to [Her]": Reasoning About Invisible Algorithms in News Feeds. Proceedings of the 33rd Annual ACM Conference on Human Factors in Computing Systems, 153-162. Seoul, Republic of Korea: ACM.

Flaxman, S., Goel, S., \& Rao, J. M. (2016). Filter bubbles, echo chambers, and online news consumption. Public Opinion Quarterly, 80, 298-320.

Fletcher, R., \& Nielsen, R. K. (2018). Are People Incidentally Exposed to News on Social Media? A Comparative Analysis. New Media \& Society, 20(7), 2450-2468.

Gelman, A. (2008). Scaling Regression Inputs by Dividing by Two Standard Deviations. Statistics in Medicine, 27(15), 2865-2873. 
Gil de Zúñiga, H., Weeks, B., \& Ardèvol-Abreu, A. (2017). Effects of the news-finds-me perception in communication: Social media use implications for news seeking and learning about politics. Journal of Computer-Mediated Communication, 22(3), 105123. https://doi.org/10.1111/jcc4.12185

Gillespie, T. (2014). The Relevance of Algorithms. In T. Gillespie, P. J. Boczkowski, \& K. A. Foot (Eds.), Media Technologies: Essays on Communication, Materiality, and Society (pp. 167-194). Cambridge, MA: The MIT Press.

Hargittai, E., Neuman, W. R., \& Curry, O. (2012). Taming the Information Tide: Perceptions of Information Overload in the American Home. The Information Society, 28, 161173.

Katz, E., \& Lazarsfeld, P. F. (1955). Personal Influence: The Part Played by People in the Flow of Mass Communications. New Brunswick, NJ: Transaction.

Kitchin, R. (2017). Thinking Critically About and Researching Algorithms. Information, Communication \& Society, 20(1), 14-29.

Lee, J. H. (2009). News Values, Media Coverage, and Audience Attention: An Analysis of Direct and Mediated Causal Relationships. Journalism \& Mass Communication Quarterly, 86(1), 175-190.

Lunt, P., \& Livingstone, S. M. (1996). Rethinking the Focus Group in Media and Communications Research. Journal of Communication, 46(2), 79-98.

Meraz, S., \& Papacharissi, Z. (2013). Networked Gatekeeping and Networked Framing on \#Egypt. International Journal of Press/Politics, 18(2), 138-166.

Messing, S., \& Westwood, S. J. (2014). Selective exposure in the age of social media: Endorsements trump partisan source affiliation when selecting news online. Communication Research, 41, 1042-1063. 
Newman, N., Fletcher, R., Kalogeropoulos, A., Levy, D. A. L., \& Nielsen, R. K. (2017). Reuters Institute Digital News Report 2017. Oxford: Reuters Institute for the Study of Journalism.

Newman, N., Fletcher, R., Levy, D. A. L., \& Nielsen, R. K. (2016). Reuters Institute Digital News Report 2016. Oxford: Reuters Institute for the Study of Journalism, University of Oxford.

Nielsen, R. K., \& Ganter, S. A. (2018). Dealing with Digital Intermediaries: A Case Study of the Relations between Publishers and Platforms. New Media \& Society, 20(4), 16001617.

Pariser, E. (2011). Filter Bubbles: What the Internet is Hiding from You. London: Penguin.

Pasquale, F. (2015). The Black Box Society: The Secret Algorithms that Control Money and Information. Cambridge, MA: Harvard University Press.

Pew. (2016). News Use Across Social Media Platforms 2016. Washington D.C.: Pew

Research Centre.

Pew. (2017a). Code-Dependent: Pros and Cons of the Algorithm Age. Washington D.C.: Pew Research Centre.

Pew. (2017b). How Americans Encounter, Recall and Act Upon Digital News. Washington

D.C.: Pew Research Centre.

Shoemaker, P. J., \& Vos, T. P. (2009). Gatekeeping Theory. New York, NY: Routledge.

Singer, J. B. (2014). User-generated Visibility: Secondary Gatekeeping in a Shared Media Space. New Media \& Society, 16(1), 55-73.

Sunstein, C. R. (2017). \#republic: Divided Democracy in the Age of Social Media. Princeton: Princeton University Press. 
Thorson, K., \& Wells, C. (2015). How Gatekeeping Still Matters: Understanding Media Effects in an Era of Curated Flows. In T. P. Vos \& F. Heinderyckx (Eds.), Gatekeeping in Transition (pp. 25-44). London: Routledge.

Thurman, N. (2011). Making "The Daily Me": Technology, Economics and Habit in the Mainstream Assimilation of Personalized News. Journalism, 12(4), 395-415.

Valeriani, A., \& Vaccari, C. (2016). Accidental exposure to politics on social media as online participation equalizer in Germany, Italy, and the United Kingdom. New Media \& Society, 18, 1857-1874. https://doi.org/10.1177/1461444815616223

van Dijck, J. (2013). The Culture of Connectivity: A Critical History of Social Media. Oxford: Oxford University Press.

Williams, B. A., \& Delli Carpini, M. X. (2011). After Broadcast News: Media Regimes, Democracy, and the New Information Environment. New York, NY: Cambridge University Press.

Zuiderveen Borgesius, F. J., Trilling, D., Möller, J., Bodó, B., de Vreese, C. H., \& Helberger, N. (2016). Should We Worry about Filter Bubbles? Internet Policy Review, 5(1), 116. 